\title{
CONSTRUCCIÓN DE NACIONALISMO MEXICANO
}

\section{Vicente Riva Palacio y su construcción de la unidad histórica de la nación mexicana}

\section{RESUMEN}

Este trabajo estudia la formación de Estado Nación en México a través de la obra de Riva Palacio "México a través de los siglos", sobre la base fusionada de dos culturas (la europea y la americana), dicha obra, es un recuento de la historia de México desde sus épocas pre-hispánicas hasta la contemporaneidad. El presente trabajo utilizó la metodología inductiva-deductiva en la búsqueda de información en los 5 tomos de Palacios, particularmente el tomo II, confrontándola con las posiciones posmodernistas de Nación, con lo que intentaré responder la formación de Estado Nación de México

en los tiempos modernos. Así este trabajo está estructurado en tres partes, capítulo I que trata sobre temas generales de Riva Palacio y la formación del futuro trabajo de la obra, un segundo capítulo estudiamos el tomo II de Riva Palacios y la confrontación con los conceptos posmodernistas y por último como un tercer punto, presentamos las conclusiones a las que hemos llegado con este trabajo.

PALABRAS CLAVES: nacionalismo, construcción, pasado histórico, identidad y unidad.

1 Magister en Historia con mención en Estudios Andinos de la Pontificia Universidad Católica del Perú. Historiador Docente universitario.E-mail:Valentin722@hotmail.com 
Abstract

This paper studies the formation of the nation state in Mexico through the work of Riva Palacio "Mexico through the centuries", on the combined basis of two cultures (European and American), this work is an account of the history of Mexico from its pre-Hispanic to contemporary times. This paper will use the inductive method, deductive in finding information in 5 volumes of Palacios, particularly Volume II, confronting it with postmodernist positions nation, which try to answer the formation of the nation state of Mexico in modern times. So this work is structured in three parts: Chapter I deals with general issues of Riva Palacios and the formation of future work of the work, a second chapter we will study the second volume of Riva Palacio and confrontation with the postmodernist concepts and finally as a third point, I will present the conclusions that have been reached with this work.

KEYWORDS: nationalism, construction, historical past, identity and unity.

\section{"Contrariamente a la}

interpretación cristiana de la

historia, canonizada por los

cronistas religiosos que le

precedió, la historia antigua de

México es un relato de

derechos humanos explicados

por sus propios

condicionamientos

geográficos, políticos o

sociales."

E n este trabajo nos proponemos explorar las características centrales de la obra historiográfica de Vicente Riva Palacio y su relación con la construcción de un imaginario nacionalista en el México del siglo XIX, en los albores de la República. Específicamente, nos interesa indagar cómo este autor y su equipo de colaboradores contribuyeron a forjar una identidad unitaria para un conjunto de pueblos que mostraba más diferencias que similitudes.

Como sabemos, las repúblicas latinoamericanas que surgen formalmente durante el siglo XIX no expresaban una continuidad histórica con unidades geográfico-culturales previas, y menos en el caso de sus élites criollas entroncadas más bien con España. Por lo que, las nacientes repúblicas, para serlo necesitaban un discurso que permitiese construir una sensación de pertenencia a un "nosotros", a una "comunidad imaginada", capaz de incluir no solo a múltiples diferencias, sino de forjar una unidad entre diferencias antagónicas. Entre quienes contribuyeron a construir esta comunidad imaginada, están los pensadores de las élites criollas que terminaron articulando narraciones, símbolos y sensibilidades a partir de un relato "histórico" dirigido a "inventar" un pasado que sea capaz de amalgamar a los pueblos del presente.

En este sentido, la obra impulsada por Riva Palacio es paradigmática de este proceso de construcción de una comunidad imaginada. En particular México a través de los siglos, es una obra que responde a la necesidad de impedir una fragmentación de una unidad basada en el dominio colonial, de aliviar un desconcierto social y de posibilitar la gobernabilidad. México a través de los siglos de algún modo es la obra que "inventa" a México como Nación, como comunidad imaginada.

Apoyándome en la Teoría Modernista de la Nación y los estudios poscoloniales, intentamos leer la obra de Riva Palacio como inventora de una "línea de tiempo" que le da una continuidad temporal imaginada, continuidad que es parte central de la invención de la comunidad imaginada que llamamos nación mexicana.

\section{MÉXICO A TRAVÉS DE LOS SIGLOS CONTEXTO Y ANTECEDENTES}

\section{Biografia (Vicente Riva Palacio)}

Vicente Florencio Carlos Riva Palacio Guerrero nació en la ciudad de México el 16 de octubre de 1832; fue hijo de don Mariano Riva Palacio, abogado liberal a quien Maximiliano escogió como su defensor en Querétaro, y nieto por la línea materna, del general Vicente Guerrero, su madre fue doña Dolores Guerrero. Estudió en el colegio de San Gregorio y se recibió de abogado en 1854 . Rehusó la cartera de hacienda que le ofrecía el presidente Juárez. Fue diputado en 1856 y 1861. 
Hábil narrador folletinesco que inventó la imagen que tenemos de la colonia (Martín Garatuza, los piratas del golfo), autor teatral, cronista de la violencia mexicana (el libro rojo), historiador, (México a través de los siglos), prisionero de Tlaltelolco, ministro de fomento que trajo el teléfono, "remodeló el paseo de la Reforma y desenterró a Palenque, representante de México en España, célebre en las tertulias madrileñas, dignificador de la narración breve como género artístico" (cuentos del general). Todo esto y más fue el inagotable Riva Palacio.

\section{Antecedentes de la obra de México a través de los siglos}

Haciendo una rápida mirada en el pasado sobre producciones bibliográficas, podemos encontrar alguno de ellos que tuvieron una significante relevancia para la historia Mexicana. Así mismo, que también fue fuente para los trabajos posteriores, con los cuales se enriqueció la obra México a través los siglos.

Una de esas primeras obras es la de Lorenzo Boturini, que era una magnífica colección de antigüedades mexicanas reúnen entre 1736 y 1743. La obsesión del viajero italiano fue recoger las pictografias y códices donde se había resumido el pasado de los pueblos aborígenes. Para Boturini, estos documentos contenían "tanta excelencia de cosas sublimes, que según Florescano, no solo puede competir esta historia con las más célebres del orbe, sino excederlas" (Florescano 2002: 275). Posterior a esta hay otra producción bibliográfica, como una respuesta a la ilustración europea, representado por el Conde de Buffon, el abate Raynal, Cornelius de Pauw y el historiador escocés William Robertson, quienes habían producido denigratorios sobre América y la incapacidad natural de los oriundos para crear obras de ciencia y cultura. Es así que Juan José de Eguiara y Eguren, respondió a esas afirmaciones con una Bibliotheca mexicana (1755), una obra monumental consagrada a mostrarse los méritos de la producción científica y literaria de los mexicanos desde los tiempos más antiguos hasta las primeras décadas del siglo XVIII (Florescano 2002: 276).

Otra obra de capital importancia es la de:
Francisco Javier Clavijero que era uno de los mayores humanistas ilustrados novohispanos que florecieron en la segunda mitad del siglo XVIII. Entre sus numerosas contribuciones sobresale su propuesta para pensar el pasado de su patria desde otro mirador, una idea que se plasmó en su obra denominada Storia antica del messico publicada en 1780 en Cesena, Italia durante el amargo exilio que compartió con sus compañeros jesuitas. (Florescano 2002: 276)

Estamos viendo los primeros trabajos que se han podido dar, estos dentro de la dominación española, el siguiente es otro trabajo que igual merece ser reconocido, como otro antecedente de la obra de Riva Palacio:

Contrariamente a la interpretación cristiana de la historia, canonizada por los cronistas religiosos que le precedió, la historia antigua de México es un relato de derechos humanos explicados por sus propios condicionamientos geográficos, políticos o sociales. Como dice Luis Villoro, "abrimos el libro de Clavijero y, de sus primeras páginas, nos encontramos con una historia en la que toda dimensión sobrenatural parece haberse desvanecido". Clavijero se vale los modelos y las técnicas del historiador occidental para escribir un relato unitario, coherente, razonado y elegante de la historia de una nación indígena. Es un relato del pueblo mexicano desprovisto de los estigmas satánicos y providencialista que propagaron los cronistas religiosos. En lugar de ver al indígena como un ser inferior, Clavijero lo contempla igual a cualquier otro ser humano. (Florescano 2002: 276-277)

Según José Emilio Pacheco advierte que el libro de Clavijero es de importancia capital para cultura americana, porque es el primero que plantea en el "siglo de las luces" una reflexión en que el europeo ya no es el centro, una primera tentativa de mostrar que hay otras culturas y otros grupos humanos diferentes de los paradigmas grecolatinos, en este campo la Historia antigua de México equivale a una declaración de independencia intelectual. De la misma forma la Historia antigua de México, al rescatar orgullosamente el pasado indígena que se convirtió en símbolo del patriotismo 
criollo y el argumento histórico para demandar la independencia de la nación.

Seguidamente fray Servando Teresa de Mier escribió en 1813. En su Historia de la revolución de nueva España para refutar las diatribas contra las insurgencias que hacían correr los realistas españoles, y para presentarlos ante Europa y los propios americanos, un alegato a favor de la independencia. La primera parte de la Historia revolución de nueva España relata el derrocamiento del virrey Iturrigaray. La segunda narra con prosa exaltada la insurrección del cura Hidalgo y las cruentas represiones desatadas contra ella por las fuerzas realistas. Inspirándose en un héroe Bartolomé de las Casas (Florescano 2002: 294-295). Mier no es solo el primer cronista de la insurgencia y uno de los actores del drama revolucionario que toma la pluma para defender la causa rebelde. Es el creador de una original argumentación histórica y política a favor de independencia. El argumento central de Mier es que el vínculo que unió a los pueblos de América con los reyes de España se fundaba en un pacto antiguo, escrito en las leyes de Indias: "un pacto solemne y explicito que celebraron los americanos con los reyes España".

La insólita interpretación del pasado que Mier plasmó en su historia produjo un doble efecto. Por un lado, su virulenta crítica de la Conquista y del dominio español que transformó los tres ciclos del Virreinato en la época negra de la historia mexicana. La historia de la revolución de nueva España es la primera obra que pone en jaque las imágenes de la conquista elaboradas por los cronistas españoles, la primera crónica de la insurrección de Hidalgo y con surtidor de argumentos, metáforas e imágenes antiespañolas.

Otro personaje que se asoma con una producción bibliográfica de suma importancia antes de México a través los siglos es Bustamante que según Florescano, expone los fundadores de la memoria nacional gracias a su obra:

La más conocida es un Cuadro histórico de la revolución mexicana que comenzó publicar en 1821 y concluyó en 1827. Es un obra escrita en forma de cartas, que se iban publicando conforme el autor las entregaba a la imprenta y que más tarde fue como reunidas en cinco volúmenes que sumaron casi dos mil páginas. Se trata de una acumulación de documentos mezclados con comentarios desordenados del propio Bustamante, difícil de entenderse por la anarquía de los asuntos tratados y la intromisión de anécdotas y asuntos triviales. (Florescano 2002: 301)

Así mismo hay otra obra de este autor, que sin duda trabajos de este tipo son y han sido una fuente para la elaboración de la obra México a través de los siglos:

La segunda gran obra de Bustamante es el Diario histórico de México, un torrente de páginas manuscritas que suman 42 volúmenes. El Diario exhibe las mismas deficiencias que se le achacan al Cuadro histórico: aglomeración desordenada de documentos, falta de rigor en la selección y presentación de los textos, comentarios e innecesaria mezcla de estos sustantivos con anécdotas triviales, garrulería patriotera, etcétera. Pero, a pesar de estas dificultades con el cuadro y el diario integraron el primer corpus documental de la insurgencia, la primera memoria escrita del acontecimiento que cambió la vida de los mexicanos y definió un nuevo rumbo para la nación. (Florescano 2002: 301)

Esta parte del texto podemos concluir mencionando, que si bien es cierto, hemos citado estas producciones como antecedentes de la obra que estudiamos, son a los que hemos podido acceder en esta oportunidad (fuentes secundarias).

\section{Coyuntura de la obra México a través de los siglos}

Los Yorkinos (federalistas) y los Escoceses (antigua élite colonial)

La oposición de intereses entre estos grupos produjo una escisión en la clase política, que más tarde se extendió al cuerpo social a través de los nuevos medios de difusión (el periodismo) y de participación política (las elecciones).

Eran grupos que continuamente se encontraban en enfrentamientos políticos, por 
acceder al poder, cada uno por su lado apoyados por la prensa.

Era una lucha constante donde, cuando uno de ellos accede al poder, el otro era perseguido, es así que cuando los yorkinos llegan al poder, empieza una campaña contra los escoceses, tratando de expulsadas del país, la misma figura sucede cuando los escoceses llegan al poder.

Conflicto Bélico entre México y Estados Unidos de América

Desde su independencia en 1821, México había tratado infructuosamente de consolidar un sistema de gobierno acorde a las necesidades del país. Así para 1846 ya habían experimentado las más diversas formas de gobierno como: Monarquía Constitucional, República Federal, República Central y Dictadura; pero ninguna había logrado establecer un gobierno sólido capaz de superar la lucha de fracciones políticas y la tremenda crisis de la economía nacional que llevaba décadas dominando las posibilidades del desarrollo.

La guerra contra Estados Unidos en 1846, evidencia el hecho de que después de 25 años de vida independiente, México sigue siendo un país inestable. Sin embargo, a la debilidad interna hay que agregar el acoso de diversas fuerzas extranjeras imperialistas que veían en este territorio como un espacio de oportunidad para expandir su poder y, Estados Unidos fue uno de estos países, así podríamos decir que el enfrentamiento armado entre estas dos naciones fue el producto de dos factores: por un lado el expansionismo y la ambición estadounidense y, por otra parte las luchas entre los distintos grupos políticos en México (yorkinos y escoceses), que no lograban agruparse en torno a un proyecto de país.

\section{CARACTERÍSTICAS CENTRALES DE LA OBRA MÉXICO A TRAVÉS DE LOS SIGLOS (TOMO II)}

\section{Estructura de la obra}

Según José Alejandro Ortiz Monasterio, el tomo 3 bien podría ser la parte central o el eje central de la obra historiográfica de Riva Palacio, pero José Alejandro considera que la esencia y lo central se encuentran en el tomo 2 propiamente redactado por Vicente Riva Palacio. No obstante, el de Riva es el tomo estratégico, pues abarca el largo trayecto de tres siglos que corresponden al embrión y origen de la nación mexicana, además Riva Palacio conoce ampliamente la historia colonial de México gracias a que tuvo acceso al archivo de la inquisición de México. Así, el tomo 2 está más cargado de teoría e incluso de filosofia de la historia (Monasterio 1999: 426). Según el análisis que hace este autor del segundo tomo, muestra que sigue un plan estratégicamente cronológico de toda la obra, una peculiaridad exclusiva del tomo de Riva al iniciarse el examen de los siglos XVII y XVIII, inserta cinco o seis capítulos en los que rompe la secuencia cronológica y ofrece una ambición de conjunto de ciertos aspectos estructurales.

La inclusión de estos capítulos que rompen el relato, aleja el tomo de Riva del calificativo de crónica, esto sin mencionar las muchas reflexiones que hace el autor a lo largo de la obra. Estos capítulos son también un signo de modernidad, pues si bien abarca aspectos convencionales como la división política, reseñó otros como el comercio y la real hacienda, las costumbres y las ciencias que interesan mucho un día, suponemos que todo esto es una influencia de la ilustración que Riva pudo conocer en multitud de fuentes, comenzando por el barón de Humboldt y el doctor Mora; pero no deja de tener un fin en la historiografía mexicana. La obra está dividida en tres "libros" que corresponden a varios siglos de dominación española. El libro primero es por mucho el más extenso, pues abarca 450 páginas, justo la mitad de toda la obra; la explicación de este desequilibrio es quizás que el siglo XVI es el más rico en acontecimientos que los que le siguieron: en primer lugar era necesario narrar la expansión de las conquistas y los avatares de la subyugación de las diferentes culturas o grupos étnicos, otra parte muchos renglones los ocupa el autor en narrar el proceso el establecimiento del gobierno virreinal en la Colonia, cuyos primeros años fueron tan turbios. Los libros segundo y tercero 
abarcan 200 y 250 páginas respectivamente. (Monasterio 1999: 426-427)

El libro primero (1521-1599) comienza con una interesante introducción y luego sigue la descripción de Tenochtitlan después de la victoria española, plena de cadáveres por doquier, y el martirio a que es sometido Cuauhtémoc por la sed de otro de los conquistadores. Sigue luego, la relación de la conquista de Michoacán y Oaxaca; en ambos casos Riva termina un análisis de la lengua de estas regiones y dice que para Michoacán no se apoya tanto en Pimentel como en sus propias observaciones durante la Guerra de Intervención, así como en los trabajos de "don Toribio Ruiz, vecino Uruapan".

El libro segundo (1600-1699) comienza con seis capítulos monográficos ya mencionados que rompe con la secuencia cronológica, para describir el estado de la colonia al terminar el siglo XVI, y son los siguientes:

I. División política. División eclesiástica. Ciudades, villas y pueblos.

II. Razas y castas.

III. Minería, agricultura, ganadería, animales domésticos.

IV. Comercio.

V. Navegación.

VI. Instrucción política, literatura y bellas artes.

Luego, el autor narra la sublevación en Topia. Enrico Martín o Martínez y el desagüe de la Ciudad de México. Expedición y Vizcaíno al Japón. Sometimiento de los yanquis. Ejecución de los treinta y tres negros. Matriz del desagüe de México. Piratas en Acapulco. Misiones en Sonora y Chihuahua. Llegada del virrey Duque de Escalona. El obispo Juan de Palafox es nombrado en lugar del Duque. Conflicto del obispo con los jesuitas. La soñada conspiración del irlandés Lampart. Llegada del nuevo virrey conde de Salvatierra. Disturbios y hambre. Insurrección en Tehuantepec. El pirata Morgan. Insurrección general en Nuevo México. Pirata Lorencillo. Llegada de un falso visitador. Reconocimiento de Texas. Sublevación en Sonora y Chihuahua.
El libro tercero (1700-1799) inicia igualmente como cinco capítulos monográficos sobre el estado de la colonia al terminar el siglo XVII, son los siguientes:

I. El territorio, su división política y administrativa. Ciudades, villas y pueblos, población.

II. Agricultura, minería y comercio.

III. La real hacienda.

IV. Religión. Costumbres.

V. Ciencias, literatura y bellas artes.

Sigue el autor su narración comentando las incursiones de los piratas. Lujo y corrupción de las costumbres. Osadía de los ladrones. Persigue el virrey a Lorenzo Boturini. Pacificación de Tamaulipas. En gobierno del virrey marqués de las Amarillas. Sublevación en Sonora. Levantamiento de Canek en Yucatán. Llega el visitador con José de Gálvez. Gobierno del virrey marqués de Croix. Extrañamiento de los jesuitas. Reformas del clero regular. Problemas con Inglaterra por Belice. Gobierno del virrey conde de Revillagigedo. Revolución Francesa, sus efectos. Expediciones a Nutka (Monasterio 1999: 428-429). Hasta aquí es solo una descripción de los contenidos más resaltantes del tomo, como algo particular es la peculiaridad, que hace distinto este tomo con respecto a los demás, es la inclusión, al final del tomo, de ciertas "consideraciones generales".

Básicamente esta es la estructura del tomo II de la producción del Riva Palacio, como antes mencionábamos, tiene algunas peculiaridades, algunos básicamente sobre la historia que vamos a citar más adelante.

\section{Sobre la introducción}

En esta parte, Riva comenta su idea de la historia y debe ser analizada con mayor detenimiento. De alguna manera se puede encontrar el mismo título de la obra México tras los siglos, que ya trae en sí su carga de teoría, pues supone la existencia de México como un ente cuya esencia es siempre idéntica, para los siglos y México permanece siempre el mismo, puede haber alteraciones o contingencias pero 
no alcanzan el ser de México; dicho de otro modo los que cambian son los siglos, pero México no (Monasterio 1999: 431). Riva señala en la introducción que el siglo XVI ha sido el más glorioso y más fecundo en grandes acontecimientos que registra la historia, un siglo de tremendas contradicciones en el que puede hallarse lo más sublime y lo más degradante; y ese siglo ha tenido una evolución convulsiva y sangrienta, la geografía del mundo el estado de los espíritus para recibir la semilla de la moderna civilización, es decir que la historia es un proceso evolutivo hacia la moderna civilización; esta es una historia determinista: hay una meta fijada desde el principio, a la que se le puede llamar la moderna civilización lo mismo que la República Independiente (Monasterio 1999: 432). Según los ojos de Monasterio, Riva es un gran personaje que ha podido plasmar con lujo y detalle los sucesos ocurridos al inicio del siglo XVI, en la etapa de México antiguo.

Sigue una descripción, de las luces y sombras de Europa en el siglo XVI, en donde destaca la figura de Carlos V que lleva sobre sus hombros el terrible peso de dos mundos, menciona Riva que la conquista fue obra de los conquistadores, no de la Corona y no tardarían los oficiales reales entrar en conflicto con aquellos. Elogia de una manera superlativa a Isabel la Cató lica, quien prohibió terminantemente la esclavitud de los indios, en la época actual y a la luz de la política y la filosofía del siglo XIX, nada parece tan fácil, tan natural y tan sencillo como la conducta de Isabel en aquellos días que dio a entender, que tenía un espíritu superior al siglo en que vivía, y de haber vislumbrado a través de las prerrogativas del vasallo los sagrados derechos del ciudadano, aquí Riva al parecer se adhiere a la doctrina del gran hombre, en este caso la gran mujer y con su sola voluntad cambió en destinos de millones de indígenas, que sería el asunto un poco exagerado que Isabel vislumbrara los progresos del ciudadano, este es otro rasgo determinista, el sentido de que se propone que la nación y sus ciudadanos ya se veían anunciando desde el siglo XVI. Tal vez la moderna civilización a que se refería antes, forma también a la luz de la política y la filosofía del siglo XIX de la cual por cierto no podía quedar fuera del Positivismo.

Entonces según Riva Palacio, la Nación y la ciudadanía ya se tenía anunciando desde el siglo XVI, muestra clara de que la Nación, ya estuvo presente mucho más antes que las teorías presentadas por los representantes de la Teoría Modernista de la Nación, del siglo XIX; Eric Hobsbawm, en su trabajo titulado Naciones y Nacionalismo, menciona que la idea sobre formación de naciones $y$ nacionalismos es propia del siglo XIX, "que presentó la historia del siglo XIX como la historia de la "construcción de naciones" (Hobsbawm 2000: 9). Hicimos esta cita porque la idea de nación o nacionalismo es propia del siglo XIX, pero vemos que Riva Palacio tiene esta idea de nación todavía desde la colonia; para sustentar aún con mayor rigor sobre el origen de nación y nacionalismo citaremos a otro investigador, quien es el historiador Joseph Dager quien menciona que "esta corriente teórica surgió con fuerza desde la década de 1980, y su principal propuesta es sostener la condición de artefacto cultural de las naciones modernas. Ernest Gellner, Eric Hobsbawm y Benidict Anderson son los principales representantes" (Dager 2009: 42). Este autor señala con precisión que efectivamente la idea de nación o nacionalismo es una construcción del siglo XIX, sin embargo vemos que Riva la concibe mucho antes, todavía en la colonia de México.

Acabamos de apreciar líneas arriba un pequeño fragmento del tomo II, donde está la posición de Isabel la Católica, según Riva Palacio tiene una posición a favor del indígena del nuevo mundo. Ahora pasemos al siguiente párrafo:

Al parecer, de un hecho histórico como proceso inevitable, predeterminado desde siempre, pero una indefectible, terrible evolución que arrojaba al activo sobre el nuevo continente. Y a la comparación de la constancia de los vencidos con el levantado espíritu de la reina en un recurso interesante, pues siendo precisamente los opuestos que se hacían la guerra, cada uno estaba cumpliendo su papel en la evolución histórica del país; de este modo el autor salva históricamente a 
ambos. Esta visión conciliadora será fundamental en Riva, aunque no deje de condenarlos a clérigos codiciosos o ávidos encomenderos (Palacio 1884: tomo II p. VII)

Señala el autor que España buscó mantener un desequilibrio entre conquistadores $y$ conquistados en todo lo tocante a la potencia guerrera, pero no hay materia de cultura y de adorno del espíritu, como popularmente se creyó, es decir que según Riva la conquista no devastó el espíritu de la cultura de los indios, lo

"Cuando Riva habla de lo

indígena, da a entender el

surgimiento de un pueblo con

raíces indígenas y española,

pero solo después de la

conquista podrán constituir un

solo pueblo ya que antes eran

reinos no solo independientes

entre sí, sino que se hacian

duras guerras..."

cual viene a ser una reivindicación, cuando menos parcial de la conquista y la época colonial (Monasterio 1999: 433). Rápidamente avanzaron las conquistas, pues los pueblos comprendían lo inútil que resultaba oponerse a quienes habían vencido al arrogante y esforzado Cuauhtémotzin. (Palacio 1884: tomo II p. VIII)

En seguida citamos otro pequeño fragmento del tomo II de Riva:

"Tan pronto como alguna de aquellas independientes nacionalidades asentadas en el gran territorio que debía formar la Nueva España, era dominada por los españoles, las fronteras desaparecían, ella entraba a formar parte del gran colonia que Cortés había adivinado, la geografia de México comenzaba a equivocarse, la legislación unificaba intereses y costumbres, y la propagación del cristianismo dedicando la fraternidad universal y la obediencia a los reyes de España, coronaba la obra creando la uniformidad de sentimientos y aspiraciones, a todo lo cual, poderosa y eficazmente distribuía la generalización del idioma español.” (Palacio 1884: tomo II p. VIII)

Acá, al parecer hay una posición un tanto conformista de Riva, afirmando que no hay nada más que hacer por ahora, porque los españoles tienen el control y se está instaurando el dominio español junto con sus costumbres, religión y gobierno.

Monasterio hace otro tipo de lectura además de eso, pues acá estaría naciendo según lectura de Monasterio el embrión de la futura República Independiente de México, que en nuestras palabras diríamos que está naciendo o al menos eso hace ver Riva, o sea el embrión de la futura nación mexicana.

Cuando Riva habla de lo indígena, da a entender el surgimiento de un pueblo con raíces indígenas y española, pero solo después de la conquista podrán constituir un solo pueblo ya que antes eran reinos no solo independientes entre sí, sino que se hacían duras guerras, la conquista apareció así como elemento de progreso hacia la meta determinada, pues al echar abajo a las monarquías indígenas abrirá el camino para la república independiente, meta y destinó del ser histórico llamado México. A la vez, Riva zanja el estéril debate entre indigenistas, colonialistas y vida, salomónicamente: tanto valen, Isabel como Fernando. Y esta procede del mestizaje poderoso que debía hacerse laborioso y de difícil evolución, en ella existía el ser de México, pero en un estado embrionario y, para ello era preciso el recorrido por un proceso histórico evolutivo para realizar su verdadero ser, la república mexicana libre, independiente y soberana que era la meta fijada por el Determinismo de Riva (Monasterio 1999: 435). Se puede notar que Riva de alguna manera justifica la presencia española en tierras mexicanas, pues parece que para él la única forma de llegar a un México republicano era necesariamente pasar por todo esto (llegada y conquista de un pueblo con mayor desarrollo), 
entonces todo este suceso de hechos lo ve como un hecho histórico.

Seguidamente pasamos a otro fragmento de Riva:

"Lento y silencioso del trabajo social, se operó incesante entre ciclos del dinero español, apresadas de que las proclamaban la división de las razas y de las castas" (Palacio 1884: tomo II p. VIII). Es decir, que de nada valieron las disposiciones legales para impedir que se formara un nuevo pueblo, pues con el tiempo las razas fueron confundiéndose, las familias enlazando los intereses, convirtiéndose en patria la tierra de los desheredados, los mandos del alma nacional. Ocurre pues una trasfiguración: la Nueva España, la Colonia, se transforma en parte, en el alma nacional.

Se puede hacer una lectura de esta posición de Riva, donde podemos encontrar la comunidad imaginada de Anderson, donde Riva estaría imaginándose la nación Mexicana.

Vamos a citar un nuevo párrafo de Riva:

"La Nueva España no fue la vieja nación conquistada que recobra su libertad después de 300 años de dominación extranjera: fuente de históricos errores y de extraviadas consideraciones filosóficas ha sido considerarla así, cuando es un pueblo cuyas embriogenia y morfología deben estudiarse en los tres siglos del gobierno español, durante los cuales con el misterio del trabajo de la crisálida y con heterogéneos componentes, formase la individualidad social y política que, sintiéndose viril y robusta proclamó su emancipación en 1810." (Palacio 1884: tomo II p. VIII)

Este párrafo es de gran interés pues echa abajo de idea de que en la fecha culminante arriba citada surgió el Anáhuac, después de solo tres siglos de ocupación extranjera. No asegura Riva si es en la Colonia donde se debe estudiar la embriogenia (sin que estudia la promoción y desarrollo del embrión) y morfología (tratado de la forma de los seres orgánicos y de las transformaciones que experimentan) del ser político que se emancipó en Dolores. Así mismo acá podemos decir que Riva está utilizando la terminología médica a favor de su argumento como sustento del nacimiento de la Nación, que en este caso vendría desde la época de la Colonia.

En seguida, Riva señala que el desarrollo del pueblo mexicano abarca el periodo del 13 de agosto de 1521 al 27 de septiembre de 1821 . Aquí hay algo curioso, el tomo de Riva llega al año de 1800, pero incluir los siguientes 21 años en esta clase, porque seguramente quiso incluir esa meta que el país estaba determinado alcanzar, morfología "viril y robusta". Es decir, la independencia y sin condenar a Iturbide, como tampoco lo hará Zárate en el tomo relativo a la Guerra Insurgente. Es decir, que la Nueva España corresponde a la etapa temprana de un pueblo en desarrollo, pero que ya es ese pueblo en potencia al menos que alcanzaría a cobrar conciencia de su individualidad y no lucharía en consecuencia, por su independencia.

En el siguiente párrafo, vamos a ver como Riva conceptualiza al criollo:

"A la muerte de Carlos II era crecido el número de los que se llamaban criollos, pueblo nuevo y raza belicosa e inteligente, que formando una clase intermedia entre españoles e indios, ejerció tal influencia en aquella naciente sociedad, que a pesar de la prevención con que se les miraba, comenzó por moderar los derechos de los encomenderos, por iniciar la idea de la igualdad, y por apoderarse de algunos puestos en la escala más baja en el clero y la administración: siguió luego preparando sordamente los ánimos para la emancipación social, y concluyó con proclamar y consumar la independencia." (Palacio 1884: tomo II p. IX)

Creemos que no está claro, la clase criolla a quien se refiere con esta frase, he aquí los protagonistas del destino ineludible del país. El autor en este pasaje no define con exactitud a qué se entiende por criollos, pero se deduce del enunciado mismo que es la "clase intermedia entre españoles indios", es decir aquellos que hoy llamaríamos mestizos (incluyendo tal vez a las castas), sin embargo advertimos una contradicción, pues en el capítulo sobre las razas en las castas Riva dirá: "los hijos del español y española que no podían considerarse como castas los llamados 
criollos", y para confundir más el cuadro en las consideraciones finales resulta que la nueva y belicosa raza, la que triunfa con la independencia, no son solo criollos, sino los mestizos. Así, cuando Riva señala a los criollos como el grupo humano fundador de la nación la "gente decente" se sentirá identificado con destino nacional; al tiempo que cuando le da a los mestizos del papel estelar, el maestro de escuela, del tratante de maíz o de café y también el obrero, sentían que ellos han forjado esa patria (Monasterio 1999: 438). Riva trata de encontrar nación (teoría modernista de la nación, que vamos a precisar en nuestras conclusiones) o mejor dicho trata de formar identidad con esta literatura, de esta manera la intensión de Riva es brindar identidad y sobre todo hacer ver que la clase criolla sea parte importante de la nación embrionaria.

De misma manera Riva no tarda en mencionar muchos abusos que se cometían en la colonia y la existencia de instituciones terribles como lo fue el tribunal de la inquisición, pero el ánimo de los dos no es condenar de un plumazo esa época, también menciona el gran valor de la recopilación de leyes de indios y el auge económico que llegó a tener la Nueva España, siendo México: "una de las más opulentas ciudades del mundo" (Palacio 1884: tomo II p. XI).

\section{La tarea del historiador}

Vamos a transcribir un pequeño párrafo que se refiere sobre la tarea del historiador:

La severa imparcialidad de la historial debe juzgar a los hombres y a los acontecimientos sin preocuparse del efecto que su fallo ha de producir en las presentes o venideras generaciones. El tribunal puede alagar las pasiones o los intereses de la multitud para alcanzar el triunfo de una causa: el diplomático cubre con su vuelo ante un gobierno los acontecimientos cuyos contornos le conviene que no se perciban: el poeta alzar sobre un pedestal de gloria al hombre que se inspira un canto. El historiador no puede ni debe más si no decir la verdad; pero como esa verdad iluminada por la filosofía del escritor afecta muchas veces formas y proporciones están muy lejos de ser las ciertas, preciso es alumbrar cada uno de los cuadros con la luz que le es propia. Si quiere juzgarse a los hombres del siglo XVI por el código de ilustración, de cultura y de ciencia que rigen en el que alcanzamos; si las pasiones religiosas y políticas de la época de Carlos V; si los hechos, las leyes y las costumbres de aquellos tiempos se estudian del siglo XIX, fallo injusto será sin duda el que se pronuncie, y los personajes quedarán tan desconocidos para el lector como los hechos de esos grandes personajes serían para ellos mismos si pudieran leyes de las crónicas de su vida escritas bajo ese sistema (Palacio 1884: tomo II p. XII).

Aquí, Riva habla propiamente de la imparcialidad que debe mantener el historiador al momento de hacer la investigación, el historiador debe decir la verdad, asimismo el historiador no debe mirar con los ojos del presente el pasado; con esta parte del párrafo nos atrevemos a afirmar que Riva tenía un alto sentido de investigación y minuciosidad para la investigación, además tenía un cierto conocimiento sobre la historia y el historiador, aparte de estas apreciaciones que Riva dice se puede, considerar que este trabajo es mucho más que una crónica, como lo calificarían sus detractores.

El siguiente párrafo es sobre lo que él llama los grandes hombres, los cuales ha dado ejemplo al mencionar a Isabel la Católica y a Hernán Cortés, citaremos este párrafo también:

Es verdad que los grandes hombres pueden producir importantes modificaciones en la estructura y en la marcha de los pueblos; pero es preciso no obligarlos, como dice Spencer, que cuando un hombre influye sobre una sociedad, esa sociedad ha influido con anterioridad sobre el hombre, todos los cambios de que él es autor inmediato tienen sus causas principales en las generaciones de que él desciende. El hombre pertenece a su siglo y el siglo no pertenece al hombre; juzgar al hombre significa conocer el siglo; pero para 
conocer el siglo se necesita estudiar a la sociedad (Palacio 1884: tomo XII p. XII).

Al parecer Riva Palacio hace una alabanza a Isabel la Católica y Hernán Cortés, porque, si nos acordamos, líneas arriba ya habíamos mencionado que Riva siente un particular afecto por Isabel la Católica, es más, señala que es la defensora de los indígenas, y asimismo habla sobre el tiempo y el espacio, donde señala que el tiempo no pertenece al hombre, pero que el hombre sí pertenece a una época determinada y un tiempo determinado que él en sus palabras lo señala como siglos; en otras palabras se puede entender que Riva nos dice; cada ser humano es producto de su tiempo y la época en el cual vive.

Riva siente alabanza por la Colonia, inclusive refiriéndose a las crónicas, las cuales hay que saber investigarlas, qué hay de verdad detrás de un relato.

\section{Capítulos más importantes de cada libro}

El libro primero comprende desde los años (1521-1599) los primeros capítulos, comienza con la narración de Cuauhtemoc, como prisionero y el cese de la resistencia con esta captura de su gobernante, este primer capítulo del primer libro comienza lo que es propiamente el inicio de la conquista, las primeras discusiones de Cortés, reparto del botín, presencia de fray Bartolomé de Olmedo, son pues los principios de un establecimiento de una colonia, los capítulos posteriores como el 3, 4 y 5 narran algunas resistencias que ofrecieron los lugareños después de la presencia española, expediciones al interior de México, algunos soldados inconformes con el reparto, asimismo Riva señala: también aquellos soldados no eran hombres completamente ignorantes, vemos entre ellos surgir a Bernal Díaz, que es un historiador; Blas Botello, que pasaba por astrólogo, y a otros varios que poseían conocimientos más o menos artificiales (Palacio 1884: tomo II p. 17). Acá podemos apreciar según Riva, que entre los conquistadores hubo personas que tenían ciertos conocimientos de alguna ciencia. Asimismo, podemos hacer una pequeña comparación a diferencia de Perú, donde los soldados españoles primeros que llegaron no tenían conocimiento alguno de alguna ciencia.

Más adelante, en la página 18 del tomo 2 , habla sobre el tormento y martirio que sufre Cuauhtémoc por cuatro españoles y cómo Cuauhtémoc muestra resistencia a pesar de la poca fuerza que le queda, asimismo todas estas torturas son con el fin de conseguir mayores tesoros, y la búsqueda minuciosa que realizó Cortés y Alderete.

Prácticamente toda la página 19 y parte del 20, explica cómo Cortés reparte el tesoro a los soldados, y la inconformidad de algunos de ellos.

Vamos a citar otro pequeño o párrafo de Riva respecto de la posición de la iglesia:

El padre fray Bartolomé de Olmedo, que no tuvo una palabra de inclinación y una frase siquiera de descontento por el martirio de Cuauhtémoc y del señor de Tlacopam, y por muchas matanzas innecesarias que presenció durante la guerra, sintió alarmada su conciencia por la alegría escandalosa con que los soldados españoles celebraban su triunfo, y temió que Dios abandonará a los conquistadores por las ofensas que en aquel convite había recibido. (Palacio 1884: tomo II p. 22)

Se puede ver, haciendo un análisis del texto, que fray Bartolomé Olmedo no hizo nada por impedir estos atropellos que han sufrido los indígenas y por el propio Cuauhtémoc, si bien es cierto que fray Bartolomé de Olmedo hizo algún comentario en contra de este acto, fue llamado de inmediato por Cortés; y Cortés justificó estos atropellos, a lo cual no hubo mayores reacciones de fray Bartolomé de Olmedo, asimismo podemos notar que la iglesia tanto en caso peruano como en México no hizo ningún esfuerzo por impedir estos abusos que sufrían los originarios, sean mexicanos o incas.

Otra observación que hacemos, es la visita de los soldados españoles al rey Caltzontzin, y a la interrogante del rey de aquel pueblo indígena donde los soldados españoles 
justifican su presencia contestando de la siguiente manera:

Contestaron los castellanos, como era natural, que el deseo de desengañar a las naciones idolatras de la ceguedad y el error en que las tenía imbuidas el demonio y el caritativo anhelo de darles a conocer al verdadero Dios y su verdadera religión, eran el móvil pequeña empresa, y que en los, en nombre de su capitán y de su monarca, ofrecían amistad y favor a todos aquellos pueblos y a sus reyes, o la guerra en caso de que su amistad fuera desechada. (Palacio 1884: tomo II p. 28)

En el pensamiento de la época esto habría sido el discurso normal de los conquistadores y de los colonizadores de ocupar otros pueblos, si bien es cierto iban en nombre de la religión cristiana, sin embargo no daban opción o posibilidad de una nueva propuesta, porque daban a entender que si no es por este medio hay otras maneras más forzosas y belicosas.

Riva, acá habla sobre naciones como también encuentra en la respuesta del rey de aquel lugar la palabra patriotismo, entonces según Riva Palacio desde su óptica, ve o entiende a los españoles como naciones civilizadoras, y cuando habla de patriotismo se refiere a la posición de aquel rey de aquel pueblo indígena, Riva no da mayores luces en este punto sobre el patriotismo.

Posteriormente, Riva señala sobre el atraso que sería la lengua más antigua y más perfecta de los mexicanos, esto continúa en el capítulo III del libro primero que se refiere a las insurrecciones entre las primeras que serán en aquel coloniaje.

Posteriores capítulos tratan sobre más expediciones al interior de México, establecimiento del gobierno y administración al interior de la Colonia, la llegada del primer virrey, señalamiento de los primeros límites del virreinato de Nueva España, establecimiento las órdenes religiosas, nombramiento de iglesias monasterios, en sí comienza la etapa de cristianización a los originarios del lugar, llegada de visitadores y su política de trabajo, el estado de la Colonia al entrar en el gobierno los opositores, instalación de la inquisición en México y el primer inquisidor Moya de Contreras, establecimiento de hospitales, etc. esto es en cuanto al primer libro el segundo capítulo que abarca desde los años 1600 a 1669, donde Riva hace los primeros análisis del primer siglo de la dominación española, México tomó un nuevo rostro con divisiones eclesiásticas, políticas, pueblos y villas, asimismo Riva hace algunas distinciones de castas y razas, hace algunas apreciaciones sobre la agricultura ganadería etc. continúa siempre la sublevación de los naturales en este caso de Topia.

Vamos a hacer referencia a algunas apreciaciones que hace Alejandro Ortiz, al respecto del libro segundo, Alejandro señala que Riva es un buen estratega manejando el orden cronológico del tiempo, así del libro segundo y tercero además señala que Riva tiene habilidades narrativas por ejemplo, sobre la descripción física del territorio. Asimismo, Alejandro Ortiz hace un análisis de uno de los párrafos donde señala que Riva va más allá de una simple narración, en este caso de las razas y castas, según Ortiz es de descripción de lo antropológico tecnológico y estaría tocando Riva de alguna manera la formación de una nación: Cita textual del tomo II.

No basta para contribuir una nacionalidad, como ha dicho un pensador de nuestros tiempos, ni la unidad de lenguaje y de la religión, ni la comunidad de intereses, ni la posición geográfica de un territorio ocupado por una gran comunidad de familias, y quizás ni aun la raza, tomándose esta palabra en el sentido de remota fuente de individualidades, pero tampoco basta tener en común una herencia de recuerdos de glorias o sufrimientos racionales, como siempre ese pensador, para formar el alma de una nación: preciso es el concurso de datos estos factores, porque las naciones como los individuos deben tener un espíritu, un alma nacional, pero también un cuerpo, un organismo material igualmente nacional. Mientras en una muchedumbre de individuos que vivan en un mismo país, sujetos a un mismo gobierno y a unas mismas leyes, 
como sucedía en Nueva España en el siglo XVI, haya una porción de ellos están sujetos por su organización a sufrir enfermedades y necesidades distintas de la otra porción, no como anomalía particular, sino como ley filosófica de la raza, eso no puede ser una nacionalidad, ni allí puede existir el alma nacional, ni los sentimientos patrióticos y políticos, que representan las pasiones de ese alma, pueden aparecer dando impulso a aquel pueblo y formando de él una gran personalidad moral. (Palacio 1884: tomo II $\mathrm{p}$. 471)

Hace alusión a Renán que ya había propuesto cómo debe ser una nación, pero vemos que Riva afirma que la nación no solo es unidad de lenguaje, religión, intereses comunes, un área geográfica habitada sino mucho más. Así, siquiera estarían los teóricos de la modernidad, porque ya sea Gellner, Hosbawm o Anderson. Quizás de alguna manera la posición de Anthony Smith, este autor menciona que la nación no solo es invento de la modernidad. Pero que sí es una construcción de la modernidad.

Por otro lado, Riva Palacios era parte importante del gobierno, en este sentido si coincidiría la posición de los modernistas. Riva cuando trabaja esta obra en particular el tomo II, vemos que polemiza con Ernest Renán, sobre qué es nación, algo que el historiador francés en 1882, Renán había planteado, donde ni lo étnico, ni siquiera el lenguaje común de un pueblo; sino la idea de nación es más que una creencia, para que haya una nación, este grupo de personas tienen que haber vivido una historia común como tiempos felices, tiempos trágicos, entonces la religión, la cultura, la raza, el idioma, el territorio quedan en segundo plano. (Renán 1987: 136)

Para Riva no es suficiente que el grupo de personas hayan vivido una historia común, sino que los individuos deben tener un espíritu un alma nacional.

Asimismo, Riva menciona dentro de este párrafo arriba citado, una cierta afinidad o acercamiento a ordenar sus teorías y su método de trabajo que sería el método historicista, romanticista o inclusive positivista.

Pero, la forma cómo Riva afirma sobre la raza, da a entender que la raza autóctona es la mejor, la raza nativa americana, además es la más evolucionada y no debe a nadie esta particularidad. Entonces, inclusive la posición de Vasconcelos que resalta la raza de bronce (mezcla entre español e indígena), se puede ver que estos discursos de Riva tienen raíz en la Colonia, como un pequeño análisis nos atrevemos a afirmar que la identidad mexicana se vino formando desde la época colonial, al menos para los ojos de Riva.

\section{Capítulos monográficos al inicio del libro III (siglo XVII)}

Este libro tercero comprende desde el año 1700 a 1799, y es el último libro de este tomo, donde Riva siempre hace un análisis al comenzar cada libro del libro anterior como ha terminado en relación al siglo en que se encuentra, saca un muestreo de la situación de cómo terminó el siglo anterior.

Si bien es cierto que Riva tiene una posición de crítica a la Colonia, pero no muestra su total disconformidad con ella, sino solo en cuanto a la administración de algunas autoridades.

\section{Continuidad histórica de la obra de Riva Palacio}

Sin duda, la obra México a través de los siglos, es una de las más grandes producciones historiográficas y literarias de su tiempo y de todos los tiempos, puesto que es una fuente primaria de incalculable valor histórico, y de referencia para cualquier investigador que quisiera estudiar la historia de México y en general comprender la invasión española en Centro América y el impacto que causó en ese entonces, una muestra de que está en plena consulta para las investigaciones de hoy, es la investigación que hizo José Alejandro Ortiz Monasterio Prieto en 1999, para una tesis doctoral, en la Universidad de Iberoamericana (México), titulada La obra historiográfica de Vicente 
Riva Palacio, y a la obra que por cierto hemos hecho bastante referencia en este trabajo.

\section{CONCLUSIONES}

Primero. Sin duda que nuestra primera impresión es la admiración que siente Riva Palacios a Isabel la Católica y a Hernán Cortez, a la primera la elogia por su defensa al indígena que es abusado por los españoles en México, y al segundo lo califica dentro de los grandes hombres.

Segundo. Justifica la presencia de los españoles en México, porque gracias a ellos se ha podido llegar a la República, menciona que sin ellos no se hubiera podido llegar al desarrollo, en parte el coloniaje es bueno para Riva.

Tercero. Riva admira a los españoles y según él la nacionalidad surge a partir de esa unión entre españoles e indios, entonces la percepción de Riva sobre España es positiva.

Cuarto. Riva trata de encontrar la nación dentro de su obra para formar identidad, no define claramente cuando habla de raza, qué es raza. Metodológicamente la obra de Riva sin duda es historicista y romántica.

Quinto. Apoyándonos en la Teoría Modernista de la Nación, este trabajo de Riva, en especial el tomo II, se puede leer a partir del postulado de Benidict Anderson, su trabajo de comunidades imaginadas, cuando Riva habla sobre el espíritu alma nacional, esto estaría dentro de la imaginación de Riva; cuando Riva afirma sobre un cuerpo, desde la posición de Anderson diríamos que se refiere a la soberanía.

Sexto. Así mismo, la obra de Riva si bien es cierto que tiene como fin forjar una identidad de la nación mexicana, no deja de ser una construcción del Estado o sea encaja claramente en los estudios teóricos modernistas de la Nación (Hosbawm, Anderson, Gellner) porque es un constructo nacional a partir de una propuesta de la élite, por consiguiente no es posible hacer una lectura con una posición de Homi
Bhabha apoyada en el orientalismo de Eduard Said.

Séptimo. Apoyándonos en la Teoría Modernista de la Nación, se puede ver lo siguiente: que la Nación es un artefacto cultural como señala Gellner, que en caso del trabajo de Riva Palacio México a través de los siglos, es un artefacto cultural porque a través de este trabajo de Riva se crea la nación mexicana; en él Riva no define claramente sobre el nacionalismo, pero señala claramente las ideas de Nación que según él, vienen desde la etapa colonial de México, con esto podemos decir que nuestra hipótesis inicial fue probar que la obra México a través de los siglos, sí contribuyó a la formación de la nación mexicana.

REFERENCIAS

ANDERSON, Benidict (1993) Comunidades imaginadas: reflexiones sobre el origen y la difusión del nacionalismo. Fondo de cultura económica. México DF.

ANNINO, Antonio y Francois-Xavier Guerra (2003) Inventando la nación iberoamericana siglo XIX. Primera edición. México. Fondo de cultura económica.

BRADING, David

1973 Los orígenes del nacionalismo mexicano. Ediciones era. México. Colección problemas de México.

BHABHA, Homi (1990) Nation and Narration. Londres. Routledge.

DAGER ALVA, Joseph (2009) Historiografía y Nación en el Perú del siglo XIX. Fondo editorial Pontificia Universidad Católica del Perú. Lima.

FLORESCANO, Enrique (2002) Historia de las historias de la nación mexicana. Edición Tauros. México.

GELLNER, Ernest (2008) Naciones y nacionalismo. Editorial Alianza. Madrid. España.

HOBSBAWM, Eric (2000) Naciones y nacionalismo. Barcelona: critica. España.

KRAUZE, Enrique (2005) La presencia del pasado. Editores Tusquets. México y España.

MONASTERIO PRIETO, José Antonio (1999) La obra historiográfica de Vicente Riva Palacio. Biblioteca virtual cervantes. Consulta: 27 de junio de 2010. http://descargas.cervantesvirtual.com/servlet/Sirve Obras/02493286211460273022202/004028.pdf.

RIVA PALACIO, Vicente (1884) México a través de los siglos. Editorial Ballesca y Espasa. Cinco volúmenes. México DF.

RENAN, Ernest (1987) ¿Qué es la nación? Editorial Alianza. Madrid. España.

SAID, Eduard (1990) Orientalismo. Primera edición. Madrid España. Madrid.

ZERMEÑO PADILLA, Guillermo (2002) La cultura moderna de la historia, una aproximación teórica e historiográfica. Colegio de México, centro de estudios históricos. México. 
